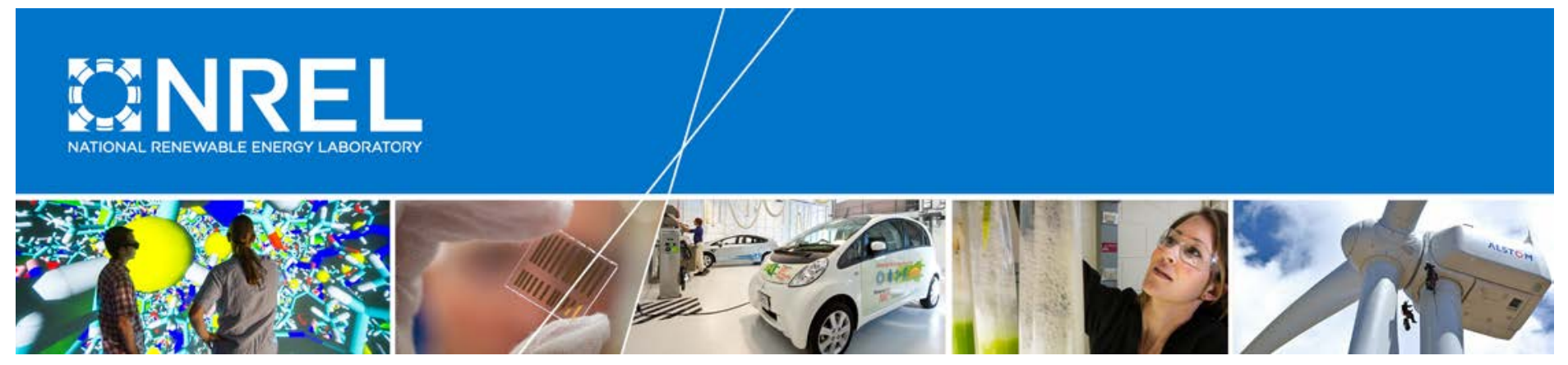

\title{
Hardware-in-the-Loop Testing of Utility-Scale Wind Turbine Generators
}

Ryan Schkoda, Curtiss Fox, and Ramtin Hadidi Clemson University

Vahan Gevorgian, Robb Wallen, and Scott Lambert

National Renewable Energy Laboratory

NREL is a national laboratory of the U.S. Department of Energy Office of Energy Efficiency \& Renewable Energy Operated by the Alliance for Sustainable Energy, LLC

This report is available at no cost from the National Renewable Energy Laboratory (NREL) at www.nrel.gov/publications.

Technical Report

NREL/TP-5000-64787

January 2016

Contract No. DE-AC36-08GO28308 


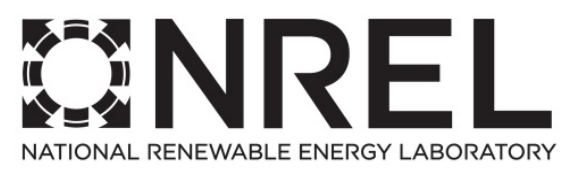

\section{Hardware-in-the-Loop Testing of Utility-Scale Wind Turbine Generators}

Ryan Schkoda, Curtiss Fox, and Ramtin Hadidi Clemson University

Vahan Gevorgian, Robb Wallen, and Scott Lambert National Renewable Energy Laboratory

Prepared under Task No. WE15.1A07

NREL is a national laboratory of the U.S. Department of Energy Office of Energy Efficiency \& Renewable Energy Operated by the Alliance for Sustainable Energy, LLC

This report is available at no cost from the National Renewable Energy Laboratory (NREL) at www.nrel.gov/publications.

National Renewable Energy Laboratory 15013 Denver West Parkway Golden, CO 80401 303-275-3000 • www.nrel.gov
Technical Report

NREL/TP-5000-64787

January 2016

Contract No. DE-AC36-08G028308 


\section{NOTICE}

This report was prepared as an account of work sponsored by an agency of the United States government. Neither the United States government nor any agency thereof, nor any of their employees, makes any warranty, express or implied, or assumes any legal liability or responsibility for the accuracy, completeness, or usefulness of any information, apparatus, product, or process disclosed, or represents that its use would not infringe privately owned rights. Reference herein to any specific commercial product, process, or service by trade name, trademark, manufacturer, or otherwise does not necessarily constitute or imply its endorsement, recommendation, or favoring by the United States government or any agency thereof. The views and opinions of authors expressed herein do not necessarily state or reflect those of the United States government or any agency thereof.

This report is available at no cost from the National Renewable Energy Laboratory (NREL) at www.nrel.gov/publications.

Available electronically at SciTech Connect http:/www.osti.gov/scitech

Available for a processing fee to U.S. Department of Energy and its contractors, in paper, from:

U.S. Department of Energy

Office of Scientific and Technical Information

P.O. Box 62

Oak Ridge, TN 37831-0062

OSTI http://www.osti.gov

Phone: 865.576.8401

Fax: 865.576.5728

Email: reports@osti.gov

Available for sale to the public, in paper, from:

U.S. Department of Commerce

National Technical Information Service

5301 Shawnee Road

Alexandria, VA 22312

NTIS http://www.ntis.gov

Phone: 800.553 .6847 or 703.605 .6000

Fax: 703.605.6900

Email: orders@ntis.gov 


\section{Table of Contents}

Table of Contents ........................................................................................................................... iii

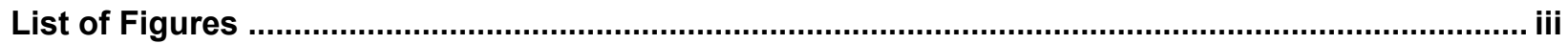

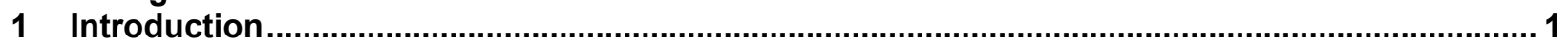

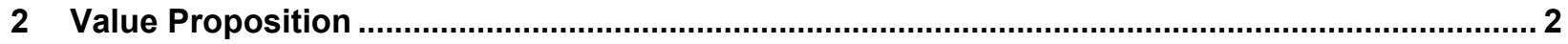

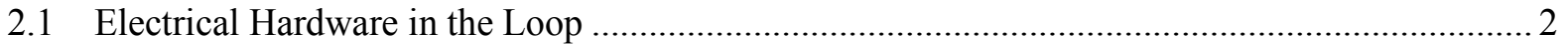

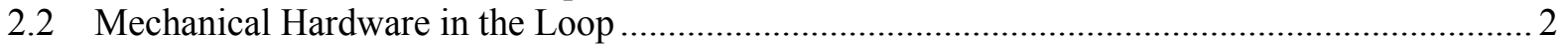

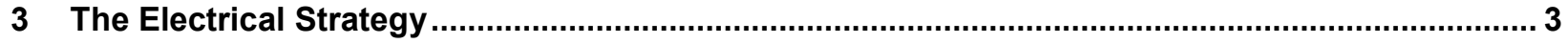

3.1 NREL Controllable Grid Interface Configuration................................................................. 3

3.2 Clemson Electric Grid Research, Innovation and Development Center Configuration................ 5

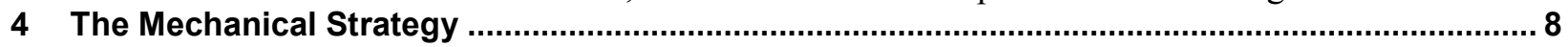

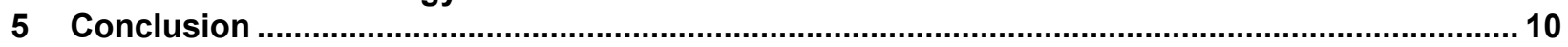

\section{List of Figures}

Figure 1. NREL's PHIL testing setup. Illustration by Vahan Gevorgian, NREL ............................... 4 Figure 2. Example of NREL's PHIL experiment. Illustration by Vahan Gevorgian, NREL .................. 5 Figure 3. The electrical single-line diagram of the Energy Innovation Center. Schematic by Curtiss

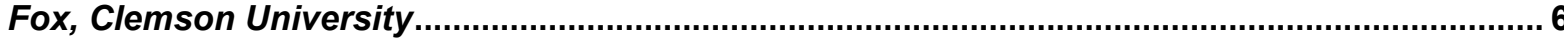

Figure 4. A typical HIL setup at eGRID. Image by Curtiss Fox, Clemson University......................... 6 Figure 5. Interaction structure of a device in the real-world environment and in an HIL test

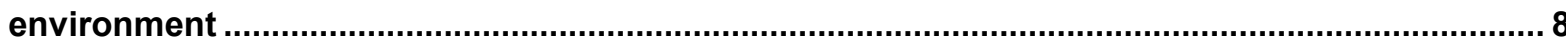

Figure 6. An interaction diagram between the device under test, the computer simulation, and the test hardware. Figure by Ryan Schkoda, Clemson University ...................................................... 9 


\section{Introduction}

Historically, wind turbine prototypes were tested in the field, which was - and continues to bea slow and expensive process. As a result, wind turbine dynamometer facilities were developed to provide a more cost-effective alternative to field testing. New turbine designs were tested and the design models were validated using dynamometers to drive the turbines in a controlled environment. Over the years, both wind turbine dynamometer testing and computer technology have matured and improved, and the two are now being joined to provide hardware-in-the-loop (HIL) testing. This type of testing uses a computer to simulate the items that are missing from a dynamometer test, such as grid stiffness, voltage, frequency, rotor, and hub. Furthermore, wind input and changing electric grid conditions can now be simulated in real time. This recent advance has greatly increased the utility of dynamometer testing for the development of wind turbine systems.

Large-scale grid integration of variable wind (and solar) generation will have a profound impact on grid stability and reliability. As a result, wind turbine manufacturers, plant operators, and utilities need to continuously adapt to evolving ancillary service markets and reliability rules and regulations, changing grid codes and interconnection requirements, improved operational practices, and so on. Under such conditions, traditional testing and certification of individual system components is no longer sufficient to ensure lower costs, reliability, and quality of the power supply. Therefore, more complex HIL testing schemes combining real power hardware and controllers with real-time dynamic simulation of other real-world components (e.g., wind rotors, power grids, market rules, and price signals) are needed to verify that wind turbine generators (WTGs) are capable of meeting their design goals in a safe and reliable manner. 


\section{Value Proposition}

\subsection{Electrical Hardware in the Loop}

HIL grid simulator testing capability provides a great deal of value to the wind power industry and other renewable energy industries, including:

- Wind power grid compliance and ancillary services testing at the multimegawatt-level under controlled medium-voltage (hereafter referred to as MV per the International Electrical Commission) grid conventions

- The ability to test for compliance with national and international electrical standards, grid codes, and interconnection requirements

- Tools for advanced controls testing and validation.

Additionally, grid simulator testing helps increase reliability and reduce integration costs of wind power generation.

\subsection{Mechanical Hardware in the Loop}

Mechanical HIL testing benefits the wind turbine testing community by:

- Allowing wind turbine test benches to be used for performance and structural testing, which is accomplished by incorporating the nacelle control system into the physical test. For example, modern wind turbines often use sensors to measure key structural responses, such as blade strain or main-shaft deflection, for the purpose of estimating mechanical loads in real time. In this paradigm, instrumented wind turbine subsystems are operating as mechanical load transducers. Measured mechanical loads are fed back to the pitch and/or generator control systems to reduce fatigue loading. HIL provides a highly realistic, controlled environment to test real-time, closed-loop, load mitigation systems.

- Providing realistic mechanical boundary conditions for the test article. The HIL system allows transient events (mechanical or electrical) that evolve over the course of seconds to take place as though the nacelle were in the field.

- Offering a more fully integrated system test beyond testing just the mechanical and electrical components. Incorporating the nacelle controller allows test engineers to observe nearly all the components of the nacelle interacting with one another in a controlled and repeatable environment. 


\section{The Electrical Strategy}

For years, the importance of hardware in the loop (HIL) for dynamometer testing has been recognized by the testing community as introducing the impacts of "missing" turbine components (e.g., the blade pitch system and wind rotor dynamics) into the testing process of wind turbine drivetrains. The same level of understanding is being developed for the grid simulator side of testing as well, in which the power hardware-in-the-loop (PHIL) capability will introduce the impacts of "missing" electrical components from the grid side. Creating a real-time PHIL test system that encompasses both the mechanical and electrical systems will also allow for greater scalability when the dynamics of an entire wind power plant or power system can be emulated.

Historically, testing the grid compliance aspects of wind generation involved a single wind turbine connected to a strong power grid (International Electrotechnical Commission 61400-21 power quality testing standard for wind turbines). But, as levels of wind penetration increase, new requirements for such testing have arisen. For example, a single wind turbine can no longer be tested in isolation from the other elements of the power system. Fortunately, PHIL-capable grid simulators can now be used to test the grid integration aspects of wind power.

Ongoing research work at Clemson University and the National Renewable Energy Laboratory (NREL) is targeted at helping the wind power industry by developing advanced PHIL testing methods that can address these new challenges. In particular, these methods combine a real-time, multimegawatt grid simulator and variable frequency drive and nontorque loading (NTL) systems with real-time dynamic simulation hardware (Real Time Digital Simulator [RTDS], Opal RT, NI PXI, NI cRIO) in both facilities to create a unique environment suitable for testing, under repeatable conditions, the full wind turbine generator drivetrain with controls and auxiliary equipment. Such simulations can model turbine behavior when exposed to the most severe perturbations coming from both grid and variable wind resource sides. In addition, suites of advanced services to the grid, such as various forms of active and reactive power controls and fault performance, can be tested under most realistic conditions.

\subsection{NREL Controllable Grid Interface Configuration}

An example of NREL's PHIL testing setup includes a dynamometer with a test article, a controllable grid interface, and the possibility of connecting additional power hardware (e.g., field turbines and energy storage) is shown in Figure 1. Additional real-time links with other facilities such as NREL's Energy Systems Integration Facility and the Idaho National Laboratory are also available, allowing NREL to use its real-time simulation resources for more advanced experiments involving additional power hardware and controls. 


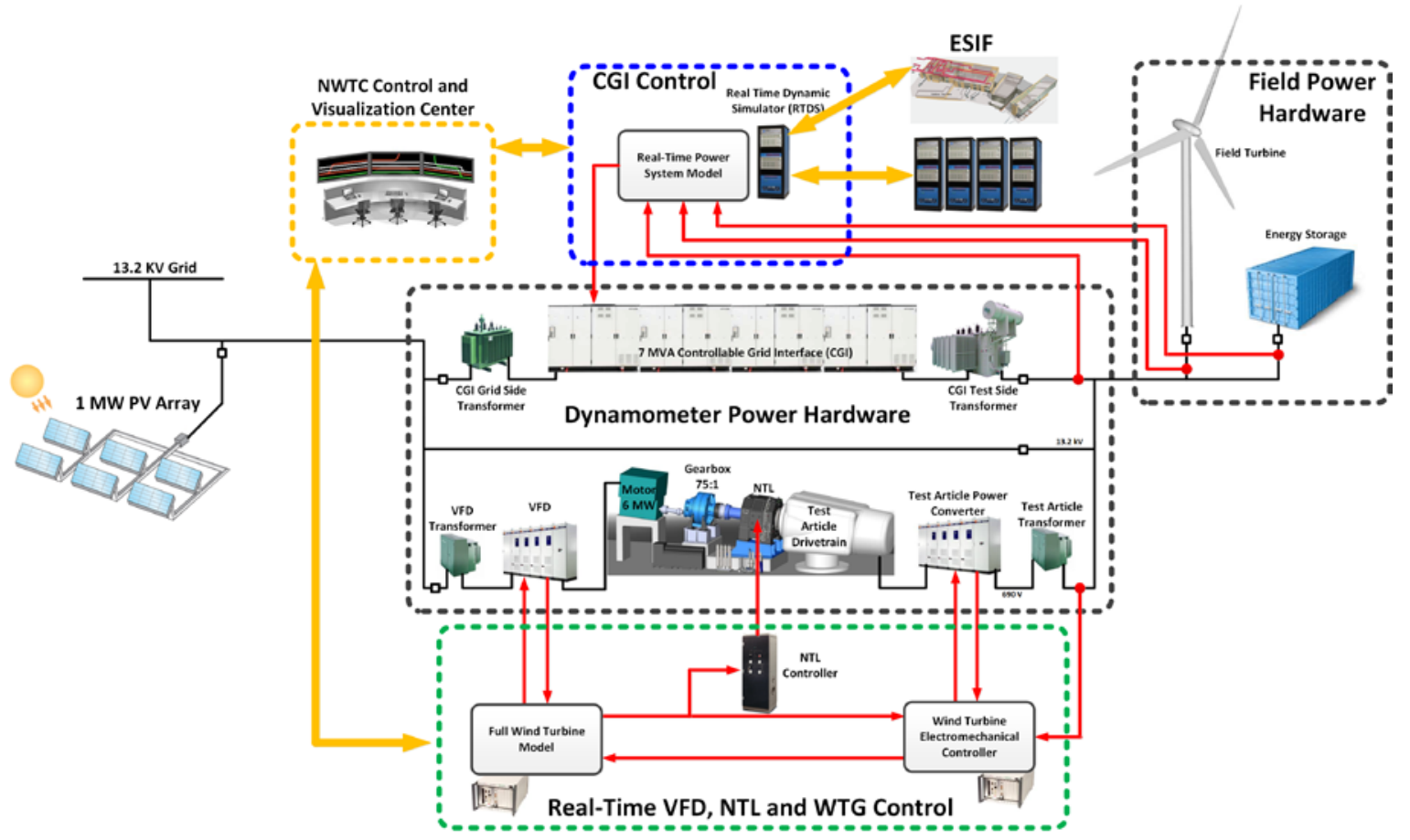

Figure 1. NREL's PHIL testing setup. Illustration by Vahan Gevorgian, NREL

One example of a PHIL application for wind turbine testing is being developed by NREL to investigate the impacts of wind active power controls and low-voltage ride-through (LVRT) controls on the structural loading of drivetrain components. For active power controls, NREL is testing new controller designs that are capable of simultaneously actively de-rating, following an automatic generation control (AGC) command, and providing primary frequency control (PFC). For LVRT controls, the focus is to evaluate the impacts of various grid code requirements on turbine loads. For this purpose, the NREL team is working on developing the experimental scheme shown in Figure 2. A real-time model of a power system consisting of conventional generators, wind power, a transmission network, and loads is simulated in RTDS, which provides MV voltage waveform set points to the controllable grid interface. At the same time, the measured MV voltage and current waveforms are supplied to the RTDS model for closedloop simulation. This and similar experimental configurations create unique PHIL platforms for testing the interactions between many wind turbine generator control loops (e.g., aerodynamic, electromechanical, and grid side) under most realistic but repeatable and fully controlled scenarios and conditions. 


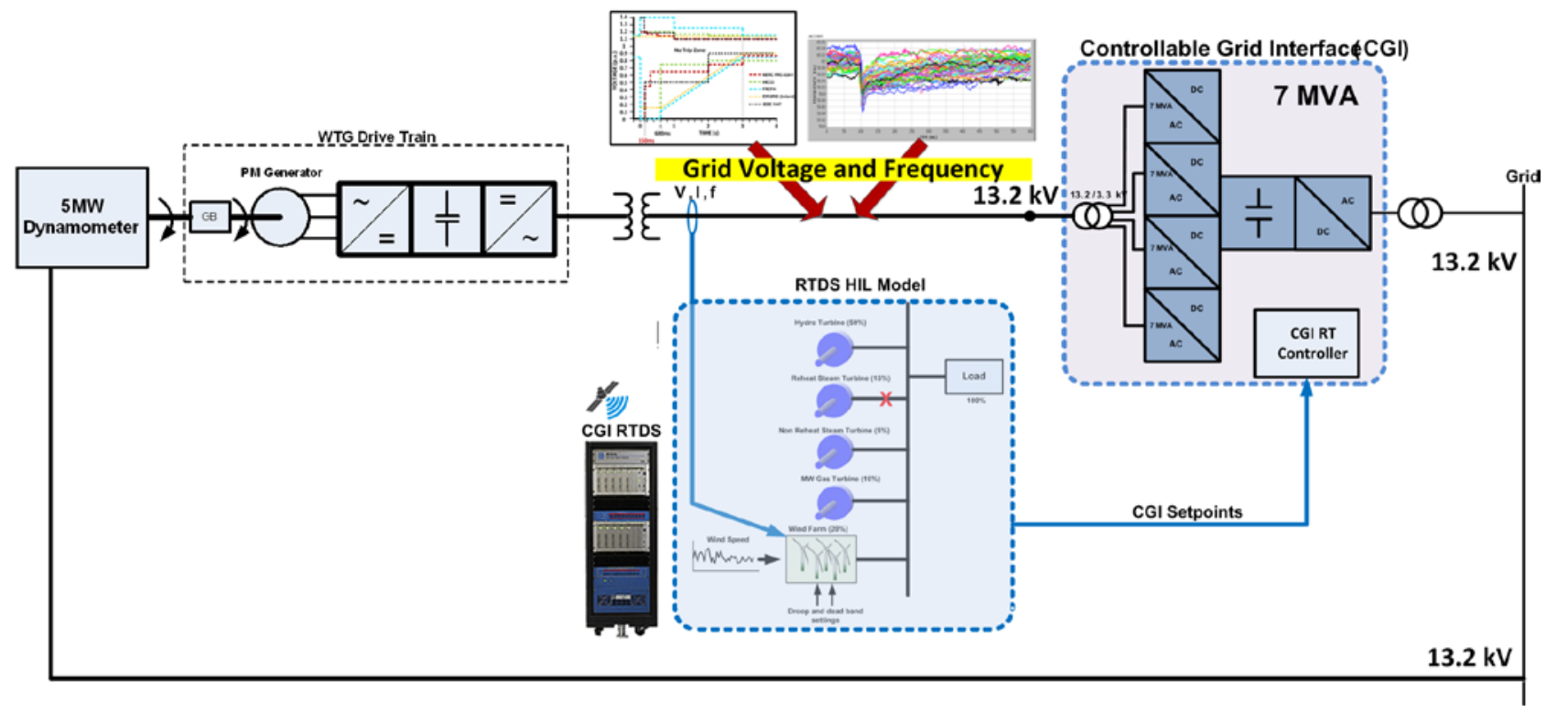

Figure 2. Example of NREL's PHIL experiment. Illustration by Vahan Gevorgian, NREL

\subsection{Clemson Electric Grid Research, Innovation and Development Center Configuration}

The initial motivation for HIL testing at the Duke Energy Electric Grid Research Innovation and Development (eGRID) Center was to provide full electrical testing for wind turbines as well as mechanical testing at the Wind Turbine Drive Train facility at the SCE\&G Energy Innovation Center at the Clemson University Restoration Institute. For this purpose, the Clemson team also developed a one-of-a-kind solution to perform fault ride-through testing by combining a reactive divider network and a large power converter. This unique hybrid method of performing fault ride-through analysis enables the research team at eGRID to investigate the complex differences between the alternative methods of performing fault ride-through evaluations, ultimately advancing the science behind this testing.

Figure 3 shows a simplified, single-line electrical diagram of the Energy Innovation Center. Switchgear is built into the system for easy coupling of the wind turbine dynamometers to eGRID. The 15-megawatt (MW) HIL Grid Simulator can also be independently partitioned off and utilized for the testing of other devices in the electrical test bay area. Power amplifier units (PAUs) are the key components of the 15-MW Grid Simulator. The modular design of PAUs allows series and parallel configurations of amplifier sections to obtain desired voltage and power levels. The installed configuration of the power amplifier consists of eight parallel converters, two per unit, with an output overvoltage capability of $133 \%$ at rated current. Each PAU consists of two sets of four series-connected H-bridge converters per phase arranged in slices. Through the use of phase-shifted carrier pulse width modulation, a large degree of harmonic cancellation is achieved. The addition of a reactive divider network enhances the system's capability to conduct fault testing and reduces the short-circuit duty of power amplifier units (PAUs). This electrically isolated circuit can tolerate up to 100-MVA fault duties. It also enables a hybrid method of performing fault ride-through testing. The reactive divider network is 
easily reconfigurable to create any symmetrical and asymmetrical fault conditions by using adjustable air-core reactors and resistor banks. Figure 4 shows a typical HIL setup at eGRID.

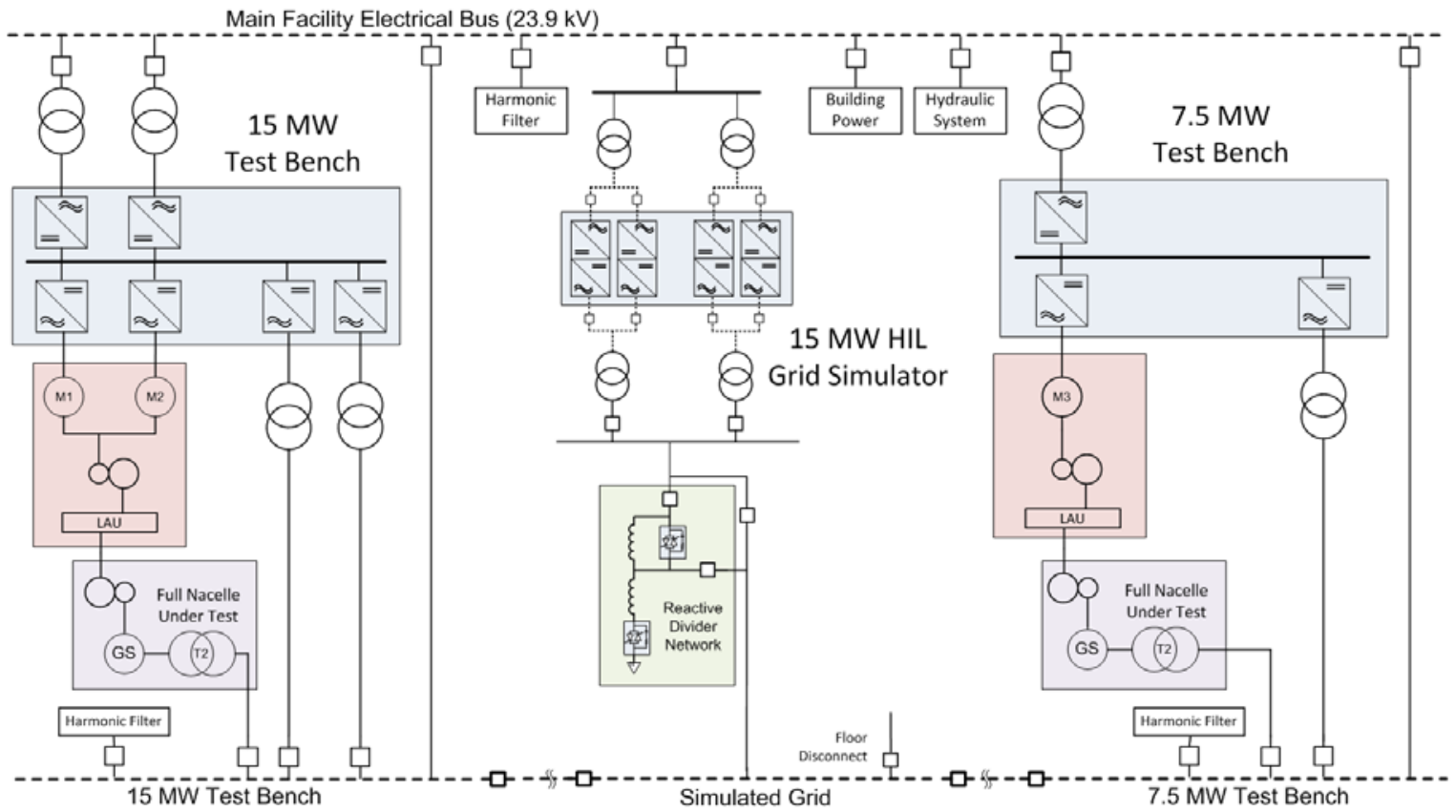

Figure 3. The electrical single-line diagram of the Energy Innovation Center. Schematic by Curtiss Fox, Clemson University

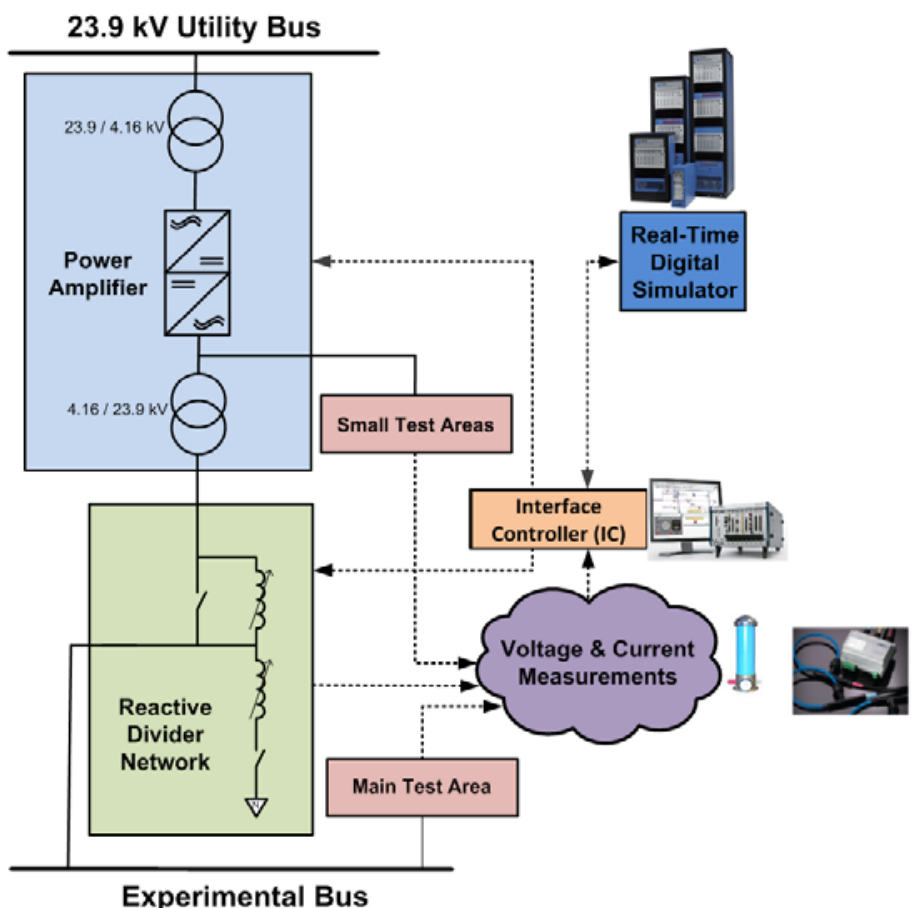

Figure 4. A typical HIL setup at eGRID. Image by Curtiss Fox, Clemson University 
The PAUs use a distributed control system based on National Instrument's RIO components with three major levels. The control system architecture matches the flexibility of the series-connected H-bridge power stage topology in the sense that each slice carries its own controller board. The slice controller connects to a mains controller that serves as a communication hub for the PAU and contactor control. The master controller is the highest and final layer of the control system and controls up to four PAUs in this configuration. The HIL application requires the coordination of additional components aside from the amplifier, so an additional control layer was added in the form of a National Instrument's PXI chassis, referred to as the interface controller. This controller communicates with the master controller digitally using a plastic optical fiber physical layer on a 12-kilohertz clock. Furthermore, it provides an instantaneous value interface and sends a serial packet containing instantaneous voltage set points for all three phases to the power amplifier. These voltage values can come from either the RTDS (HIL application) or can be internally generated according to the loaded test protocol. 


\section{The Mechanical Strategy}

Both the Clemson and NREL dynamometers are configured similarly from a mechanical perspective. All of them use an electric prime mover, a speed-reduction gearbox, and a load application unit (LAU) or nontorque loading (NTL) unit to apply nontorque loads at a point along the main shaft of the device under test (referred to as the hub point). These loads can be specified ahead of time or calculated in real time as part of an HIL testing scenario.

HIL testing is useful when the device under test has an influence on the loads it experiences. In the real world, a device may interact with its environment, thereby influencing the input coming from the environment. In a test environment, the effect of the device output must be calculated by a real-time simulation and the test equipment must be made to replicate these effects at full scale (see Figure 5).

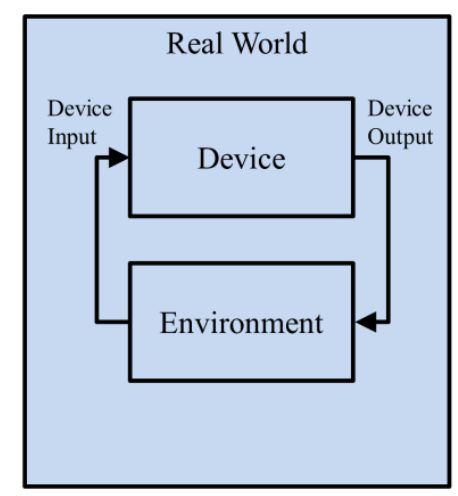

Figure 5. Interaction structure of a device in the real-world environment and in an HIL test environment

In the case of a wind turbine, the loads experienced at the hub point depend on both the input to the turbine (i.e., the wind) and the control action of the turbine (i.e., the pitch, yaw, and generator torque). As a result, an HIL testing strategy will allow the test bench to provide loading conditions that are consistent with both the system input (i.e., the wind) as well as the control actions coming from the nacelle.

At both the Clemson and NREL test benches the nacelle being tested is mounted to either a short tower or directly to the floor; the hub of the nacelle (including the blades and pitch actuation systems) is removed, and the nacelle is coupled to the test bench at the end of the main shaft. The mechanical properties of the nacelle are altered significantly by removing the hub and attaching the nacelle to a test bench. Not only must the effects of the now-missing hub be emulated, but the different mass, stiffness, and damping properties of the test bench must be compensated for as well.

Figure 6 shows a proposed wind turbine nacelle HIL configuration designed to account for the effects of the missing hub and being mounted to a test bench, and to compensate for the structural properties of the test bench. With this configuration, the control actuation signals for the blade pitch mechanisms and the yaw mechanism are intercepted and routed to a real-time model of a wind turbine. This model takes those control signals, along with a simulated wind field, and computes the loading at the interface of the nacelle. The test equipment then replicates 
these loads at full scale. This control loop allows the device under test to influence the loads it is experiencing the same way it would in the field.

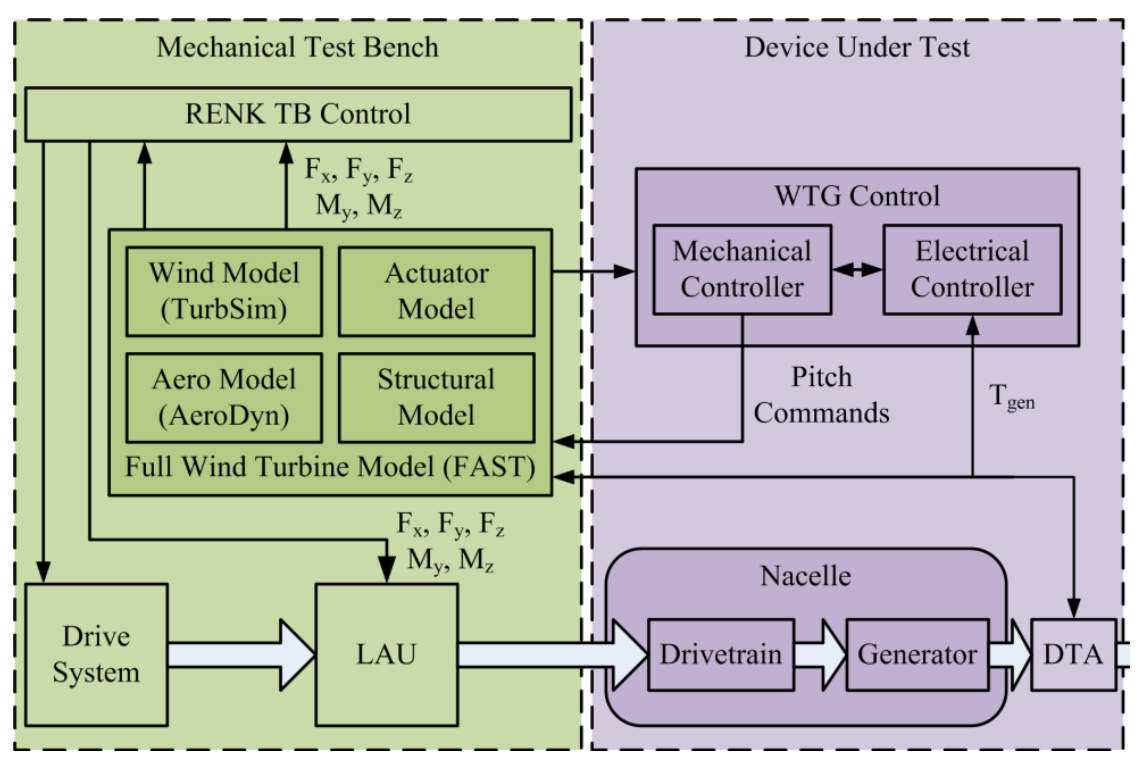

Figure 6. An interaction diagram between the device under test, the computer simulation, and the test hardware. Figure by Ryan Schkoda, Clemson University

Note: Abbreviations in Figure 6 include $\mathrm{TB}=$ test bench, $\mathrm{F}=$ force, $\mathrm{M}=$ moment, DTA = down tower assembly (power electronics), and Tgen $=$ torque, generator. 


\section{Conclusion}

The arrival of faster computing capabilities coupled with modern wind turbine dynamometer testing provides a new and unprecedented opportunity for wind turbine developers. Now, testing time of prototype wind turbines can be significantly reduced. In parallel, design models can be validated and upgraded using dynamometer hardware-in-the-loop data, which are quicker and less expensive to collect than field-based experimental data. 